\title{
SOCIAL PRECARIOUSNESS AND ACCESSIBILITY TO THE URBAN TRANSPORT IN THE MEGACITIES, CASE STUDY OF A PERIPHERAL COMMUNE OF CASABLANCA, MOROCCO
}

\author{
I. $\operatorname{Hbiak}^{1,2, *}$, A. Adidi $^{1}$, E. El Brirchi ${ }^{2}$ and J. P. Nicolas ${ }^{3}$ \\ ${ }^{l}$ Institut National d'Aménagement et d'Urbanisme (INAU), Madinat Al Irfane, Rabat, Morocco - ishak.hbiak@ gmail.com \\ ${ }^{I}$ Institut National d'Aménagement et d'Urbanisme (INAU), Madinat Al Irfane, Rabat, Morocco - a2adidi@yhao.fr \\ ${ }^{2}$ Ecole Hassania des Travaux Publics (EHTP), Km 7 Route d'El Jadida, Casablanca, Morocco - hbrirchi@ yahoo.fr \\ ${ }^{3}$ Ecole Nationale des Travaux Publics de l'Etat (ENTPE), Rue Maurice Audin, Vaulx-en-Velin, France - jeanpierre.nicolas@entpe.fr
}

KEY WORDS: Transport, Poverty, urban sprawl, Casablanca, GIS, survey

\begin{abstract}
:
The aim of this research is to study the relationship between transportation and poverty. Indeed, the non-existence, lack or weakness of the supply of transport, poor accessibility to the means of transport and thus also to the zones of economic activity for the population can possibly make their economic and social situations more precarious.

As for a study area we chose the city of Errahma at Dar Bouazza Commune as a peripheral areas of Casablanca on which we analyze accessibility to the zones of economic activity in the Casablanca region through Geographical Information Systems (GIS).

To complete our analysis, we conducted a survey of 100 households in the peripheral city. This survey aims to study the difficulty of these households to access economic activity areas as well as the high general cost to pay for their trips.

Our field study confirmed the results obtained by the GIS and shows that choosing to live in a peripheral zone like Errahma can make families poorer because of, among other things, the lack of accessibility to public transport and therefore the lack of accessibility to areas of economic activity.
\end{abstract}

\section{INTRODUCTION}

Casablanca is the first metropolis of Morocco and the Maghreb, and one of the largest cities on the African continent. The area of Grand Casablanca is spread over $1615 \mathrm{~km}^{2}$.

The city of Casablanca has a population of nearly 4 million, including a good part of the young population. The economic power of the city of Casablanca appears in the fact that it alone generates a quarter of the GDP of Morocco.

Urban transport is one of the major challenges for the economic development of the city of Casablanca, as is the case for large cities in developing countries (Vasconcellos, 2014). A good planning of the transport systems would allow a certain gain for the operators and industrial and economic actors of the metropolis and will lead to sustainable urban mobility (Banister, 2008).

The urban transport plan in Casablanca showed the existence of several problems of public transport supply in the city. Public transport has a low participation in the total mobility of the population of the Casablanca region. Indeed, buses alone account for $13 \%$ of total trips. It would not exceed $15 \%$ even including the Tramway part. This situation encourages semicollective and non-institutional transport at the expense of institutional transport (Godard, 2008) (Le Tellier, 2007).

The city of Casablanca is very much populated. Indeed the economic capital of the kingdom comes in fifth place in the ranking of the most densely populated cities on the planet according to the World Economic Forum.
This increase in density also involved in time a very important urban sprawl, combined with a low public transport offer, has meant difficult mobility conditions for the peripheral population. What makes urban mobility less sustainable (Godard, 2013). These conditions may affect the economic opportunity of the population generally known for a high level of poverty (Pathak et al., 2017).

Our research has three objectives. The first is to measure the urban sprawl of Casablanca in the peripheral area of Dar Bouazza, using satellite images, on several dates between 2003 and 2018, analyzed by remote sensing techniques and geographic information systems (GIS).

The second objective is to analyze the difference in travel conditions of this peripheral population with that of Casablanca. We have identified, analyzed and compared several indicators that reflect the situation of the generalized cost of transport of the population concerned.

Thus, we chose to calculate two indicators: the average time of an individual trip and the cost ratio of monthly trips compared to the total expenditure of households.

The third objective is to know the opinion of households in Dar Bouazza about the negative effect of the inadequacies of public transport on their economic opportunities.

To meet these two last objectives, we conducted a household trips survey, whose objectives are broader. This survey involved a sample of 100 households in this area shown in Figure 1.

* Corresponding author 
Statistical analysis of the survey data will be used to assess individual travel time and the monthly cost of household travel. It will also allow us to probe the opinions of this population about the effect of public transport conditions on their career opportunities and their professional situations.

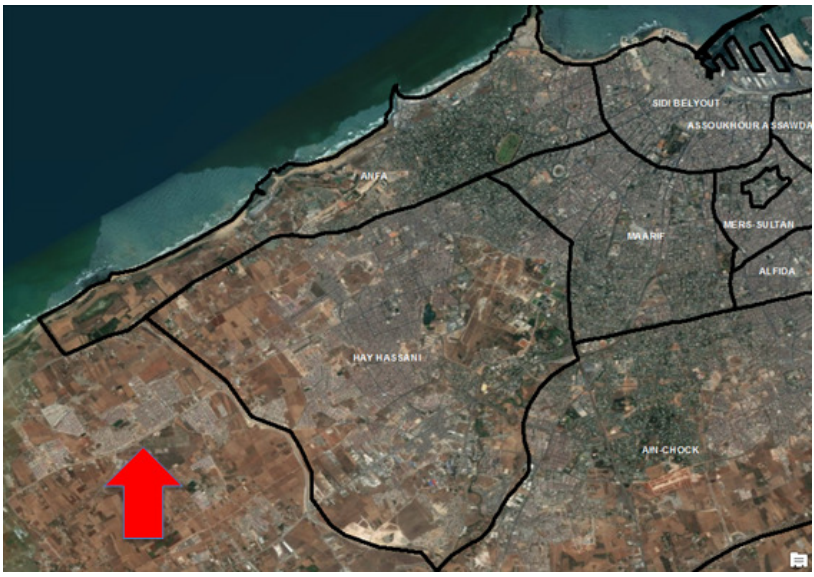

Figure 1: Peripheral commune concerned by the household survey.

\section{MEASURE OF THE URBAN SPRAWL AT DAR BOUAZZA}

\subsection{Urban sprawl and GIS}

Urban growth or urban sprawl is a theme that mobilizes researchers from several disciplines: geography, spatial planning, urban planning, ecology, economics, etc. (Demaze, 2010). The method of evaluating the urban sprawl remains paramount: how to measure the sprawl of an area and analyze its effects?

The significant difficulties and disadvantages of traditional methods of monitoring urban sprawl have implied a growing interest in the mapping and use of satellite images and the use of Geographic Information Systems (GIS), and their applications to track urban growth in general (Epstein et al., 2002).

\subsection{Study area}

Our work is interested in studying the peripheral commune of Dar Bouazza, which spread over an area of 125 square kilometers in the South West of the city of Casablanca. Administratively, the city is part of the province of Nouacer. Its population was 115,000 in 2004 and increased to 150,000 , according to the General Population and Housing Census of 2014.

The population of the commune of Dar Bouazza knows a certain social mix. Indeed, a rich population lives in certain areas of the municipality. But next to it, there is a poor population that has been relocated to certain areas like the of Errahma.

The commune of Dar Bouazza is served by few bus lines, with low frequency, in addition to semi-collective taxis. This low public transport offer has encouraged non-institutional transport, especially in the poor areas of the commune.

This area has experienced rapid urbanization in the last few years. Its population has also increased rapidly. It is one of the areas where Casablanca has spread.

\subsection{Sources of data and software used}

As part of our research topic, we used satellite images of three different dates: 2003, 2014 and 2018.

The 2003 image is obtained from the Landsat 5 TM satellite. The 2014 image comes from the Satellite LandSat 8 and the 2018 image is obtained from the Sentinel-2 satellite.

It should be noted that all the satellite images were projected in the Moroccan geodetic coordinate system Merchich / Lambert Zone 1.

As part of this study we also used the following software: Erdas Imagine for satellite image processing and ArcGIS for spatial analysis and cartographic layout.

\section{4 measuring urban sprawl by remote sensing}

Our approach, is based initially and for each given date, on the computation of the spectral indices starting from the visible and infrared bands of the satellite data used and this to extract neochannels on vegetation, water and buildings.

Indeed, we calculated three indices: the index of vegetation adjusted by the soil, the index of the waters and the index of the surfaces built.

The vegetation index is obtained from the near infrared and red bands. In our study and in order to minimize the influence of soil, we chose the soil-adjusted vegetation index (SAVI) (Huete, 1988).

We also calculated the Normalized Difference Water Index (NDWI) (McFEETERS, 1996). The NDWI formulation produces an image in which positive data values are generally open water areas, while negative values represent bare or vegetated land.

The Normalized Difference Built-up Index (NDBI) index is used to extract constructed surfaces (Zha et al., 2003). This index developed is computed from the near-infrared and midinfrared spectral bands.

In a second step, we grouped these neo-channels into a RGB color composition image that will be subject to unsupervised classification using the well known Iterative Self-Organizing Data Analysis Technique (ISODATA) method (Mundia \& Aniya, 2005) (Martellozzo \& Clarke, 2011).

The urban sprawl of Casablanca was also evaluated in previous dates. We cited her for example (GADAL, 2005), and (Gadal, 2008).

For each given date, we mapped and calculated the built-up area. The conditional crossing between the different dates made it possible to bring out the situation of the change of these builtup area with the corresponding statistics. 
we analyzed the changes of the built-up areas extracted between the three dates. This extraction was performed by a classification applied to a colored composition image of the three indices used. This treatment allowed to have a thematic image with two values: built and not built.

\subsection{Result 1: Comparison between 2003 and 2014}

The first result is presented in Figure 2, which gives the comparison of the built-up areas at Dar Bouazza between 2003 and 2014

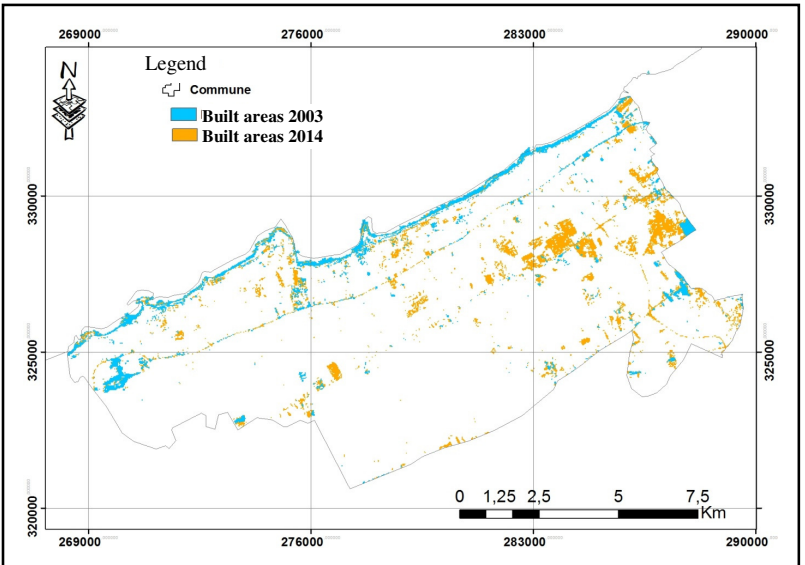

Figure 2: Comparison of the built-up area at Dar Bouazza between 2003 and 2014

The evolution between 2003 and 2014 was very important, since it doubled the surface of the built-up areas from $5.3 \mathrm{~km} 2$ to almost $10 \mathrm{~km} 2$, which represents an increase of more than $88 \%$ of the built surface area. This development has been as important in the demography of the commune, which has increased from 111,000 to 150,000 inhabitants between the two years and therefore an evolution of $35 \%$.

\subsection{Result 2: Comparison between 2014 and 2018}

Figure 3 shows the comparison of the built-up areas at Dar Bouazza between 2014 and 2018

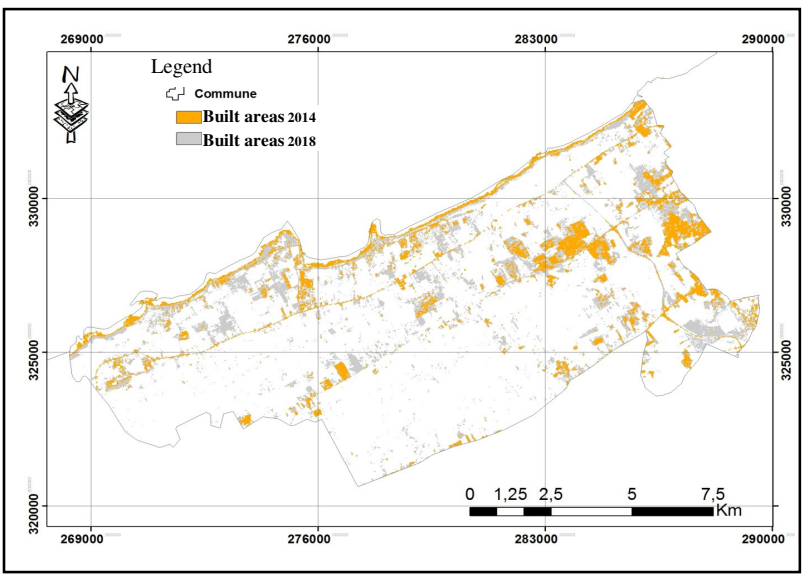

Figure 3: Comparison of the built-up areas at Dar Bouazza between 2014 and 2018
The rapid evolution between 2003 and 2014 has always occurred between 2014 and 2018. The results of the analysis between these two dates indicate an evolution of more than 14 $\mathrm{km}^{2}$, which means that the built surface has more than doubled .

This urban sprawl of Casablanca in the Dar Bouazza area has condensed a poor population in a large part of this area. This population also suffers from a weakness in the public transport supply, which would result in a high cost and time of travel. The next part of the study aims to calculate indicators concerning the cost and time of travel of this peripheral population.

\section{CALCULATION OF TIME AND TRAVEL COSTS FOR DAR BOUAZZA'S INHABITANTS THROUGH THE HOUSEHOLD TRIPS SURVEY}

We conducted a household trip survey, which targeted a hundred households in the outlying town of Errahma in the commune of Dar Bouazza.

This survey had several objectives, including estimating the costs and travel time of peripheral household members. It involved 878 trips of 391 household member.

In this research, we were able to calculate the time and the cost of travel, as well as the total monthly household expenditures in the peripheral city of Errahma through the analysis of data from our household trip survey. We also calculate the ratio between the total monthly cost of household travel and the total monthly expenditure.

In addition, we were able to compare these results with the data from the household survey carried out in 2004 as part of the Urban Travel Plan for the Casablanca region. We also compared our results with recent statistics on households (2016) in Casablanca and Morocco.

After data capture, analysis and statistical processing of our survey, we were able to obtain the results presented in the following paragraphs.

\subsection{Travel times for the population of Dar Bouazza}

Figure 4 presents the results of the statistical analysis of household data for the calculation of travel times.

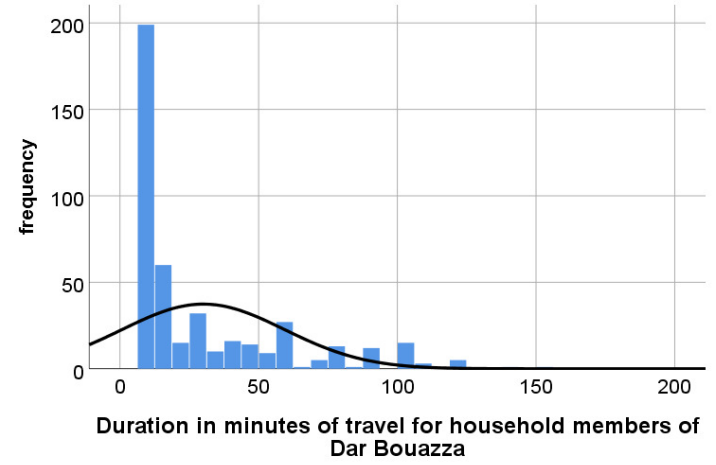

Figure 4 : results of the statistical analysis of household data for the calculation of travel times. 
We calculated the average duration of travel from the Dar Bouazza area and compared it with the average travel time obtained from the 2004 Casablanca Urban Travel Plan survey data.

For the population of this zone the average duration of a trip is 30 minutes. The "Urban Travel Plan" of Casablanca region statistics gave an average duration of 23.2 minutes per trip. This corresponds to an average duration in Dar Bouazza, 29\% higher than that of the region of Casablanca.

In addition we found that the minimum duration of the $20 \%$ of the longest trips of the population of this zone exceeds 51 minutes.

\subsection{Transport cost compared to the total monthly expenditure of households}

We also calculated the ratio between the total monthly cost of household travel for all modes of transportation and the total monthly expenditure. Figure 5 shows the distribution of this ratio.

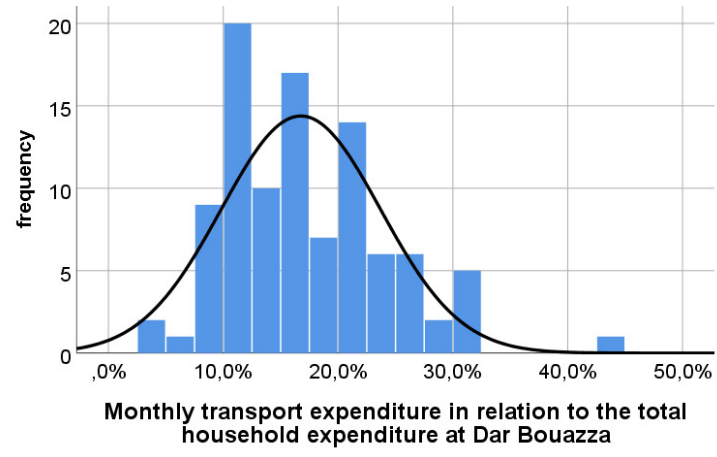

Figure 5 : Transport cost compared to the total monthly expenditure of households

The results of our analysis show that for the Dar Bouazza area this ratio of what transport represents to total household expenditures is on average $16.8 \%$. Knowing that it varies significantly between $3 \%$ as a minimum and $43 \%$ as maximum. In addition, our statistics show that for $25 \%$ of households in Dar Bouazza, transport costs exceed $20.9 \%$ of total expenditures, which is a high percentage.

This result is more than double the cost of transportation for an average Moroccan. According to the results of the 2013/2014 National Household Consumption and Expenditure Survey published in 2016, the percentage of the expenditure for transport for one person is $7.1 \%$ (in 2014) on average (Haut Commissariat au Plan, 2016)

This comparison shows that transport costs are weighing on household budgets in the peripheral areas of Casablanca, taking into account the example of Dar Bouazza. Indeed, many of these households in these areas are in "transport poverty" (Lucas et al., 2016) and (Hbiak et al., 2018).

\section{WEAKNESS OF PUBLIC TRANSPORT AND LOSS OF ECONOMIC OPPORTUNITY}

4.1 Accessibility to economic activity areas from the commune of Dar Bouazza

We have mapped the most important economic activity areas in the Casablanca region. Figure 6 shows the result obtained.

We note on this map that the most important activity areas of the region is located north of Casablanca, while the studied city is the opposite (South West) of the city.

This map shows the location of the most important economic zones within the ranges between 5 and 40 kilometres.

The analysis of this figure shows that the distance between Dar Bouazza and the most important activity zones is between 10 and 40 kilometres.

Given the conditions of the collective transport of Casablanca, this distance can correspond to a time of displacement which exceeds $2 \mathrm{~h}$ in certain cases, which is difficult as a condition of the displacements for the inhabitants of this zone.

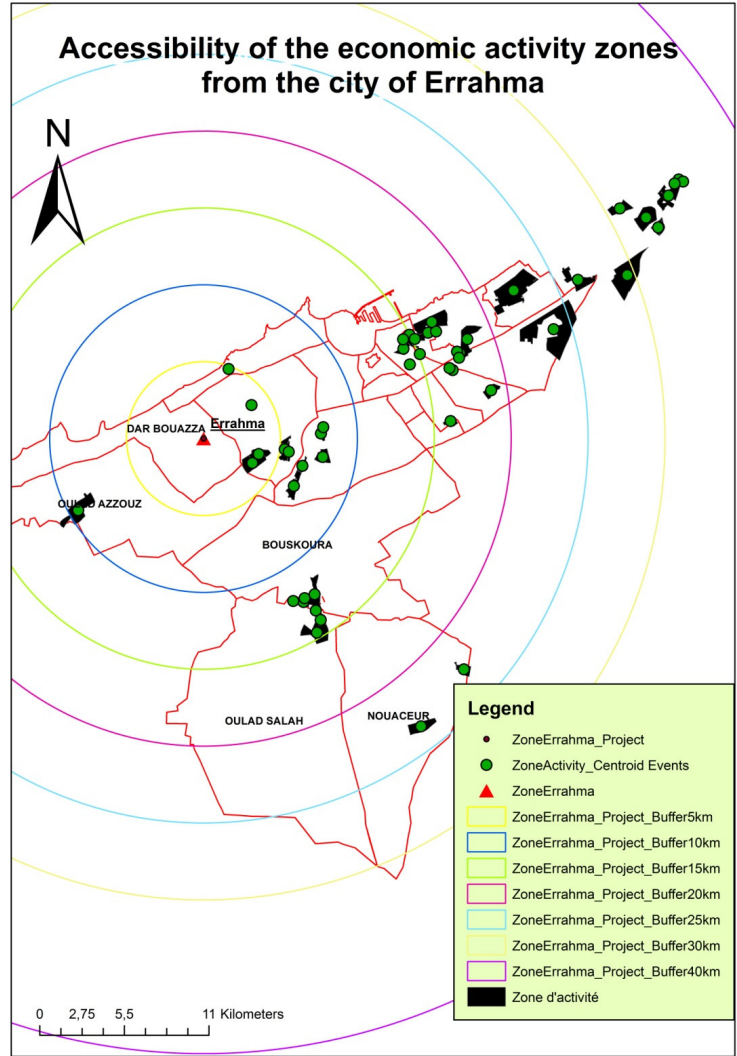

Figure 6: Accessibility of the economic activity zones from the city of Errahma

\subsection{Loss of economic opportunity}

The zones of economic activity of Casablanca are hardly accessible from the commune of Dar Bouazza according to the previous figure. This could compromise the economic opportunities of the population of this peripheral area. 
This hypothesis was tested and confirmed by our household trips survey.

Thus, we asked the following question to households in this area: Do you think that the state of public transportation has had an impact on your career opportunities or your economic situation?

In fact, $27 \%$ of households in Dar Bouazza commune reported a negative effect of public transport conditions on their economic opportunities and professional situations.

We can therefore conclude, according to the households of Errahma, that the conditions of mobility in the peripheral areas is a factor of impoverishment of the resident population in the periphery.

\section{CONCLUSION}

Our work has shown that the urban sprawl of Casablanca in the commune of Dar Bouazza was important in the last fifteen years.

This large sprawl, which concentrated a relatively poor population on this area, was not accompanied by a policy of consolidation of the public transport offer on the commune of Dar Bouazza.

Our work has shown that the peripheral population of Dar Bouazza has a higher average travel time budget compared to a resident of the Casablanca region.

The results of our analysis show that transport costs are weighing on household budgets in the peripheral areas of Casablanca. Transport costs compared to total household expenditures show that these peripheral households pay more for their trips than Moroccan households or households in the Casablanca region. We have found that many of these households in these areas are in "transport poverty".

This high generalized cost (essentially the price and the time) of the displacements of the inhabitants of Dar Bouazza, justifies the declared opinion of this population on the negative effects of the public transport on the economic opportunities of the peripheral households.

These results question the choice of the urban planning model of Casablanca, the public transport policy of the region as well as the link between transport and urban planning.

They push us to ask more questions about the notion of equity in public transport and the role of inequality of supply in the pauperization of peripheral households.

\section{REFERENCES}

Banister, D. (2008). The sustainable mobility paradigm. Transport Policy, 15(2), 73-80.

Demaze, M. T. (2010). Un panorama de la télédétection de l'étalement urbain. ESO Travaux et Documents, Espaces et SOciétés - UMR 6590, pp. 99-124. Retrieved from https://halshs.archives-ouvertes.fr/halshs-00508974/document.
Epstein, J., Payne, k., Kramer, E., (2002). Techniques for mapping sub urban sprawl Photogrammetric Engineering and Remote Sensing, 63(9), 913-918.

Gadal, S. (2005). Urbanisation et dynamiques de peuplements: Casablanca, 1994-2002. UMR.

Gadal, S. (2008). Télédétections thermiques infrarouges des concentrations urbaines au Maroc. Cybergeo: European Journal of Geography.

Godard, X. (2008). Transport artisanal, esquisse de bilan pour la mobilité durable. In Codatu XIII. Hô Chi Minh Ville(Vietnam). Available at: http://www. codatu. org/english/conferences/codatu13/CodatuXIII-CDrom/codCDGodard1. pdf.

Godard, X. (2013). Comparisons of urban transport sustainability: Lessons from West and North Africa. Research in Transportation Economics, 40(1), 96-103.

Haut Commissariat au Plan. (2016). Présentation des résultats de l'Enquête Nationale sur la Consommation et les Dépenses des Ménages.

Hbiak, I., Adidi, A., Hassan, E., Brirch, E., \& Nicolas, J. (2018). Analysis of the transport - precariousness relationship in the peripheral areas of Casablanca. MATEC Web of Conferences, 200(00023).

Huete, A. R. (1988). A soil-adjusted vegetation index (SAVI). Remote Sensing of Environment, 25(3), 295-309.

Le Tellier, J. (2007). Les services des taxis collectifs dans les grandes villes marocaines: une alternative aux déficiences des transports institutionnels. Le Taxi, Solution d'avenir Pour Les Mobilités Urbaines.

Lucas, K., Mattioli, G., Verlinghieri, E., \& Guzman, A. (2016). Transport poverty and its adverse social consequences. Proceedings of the Institution of Civil Engineers - Transport, 169(6), 353-365.

Martellozzo, F., \& Clarke, K. C. (2011). Measuring urban sprawl, coalescence, and dispersal: a case study of Pordenone, Italy. Environment and Planning B: Planning and Design, 38(6), 1085-1104.

McFEETERS, S. K. (1996). The use of the Normalized Difference Water Index (NDWI) in the delineation of open water features. International Journal of Remote Sensing, 17(7), 1425-1432.

Mundia, C. N., \& Aniya, M. (2005). Analysis of land use/cover changes and urban expansion of Nairobi city using remote sensing and GIS. International Journal of Remote Sensing, 26(13), 2831-2849.

Pathak, R., Wyczalkowski, C. K., \& Huang, X. (2017). Public transit access and the changing spatial distribution of poverty. Regional Science and Urban Economics, 66, 198-212.

Vasconcellos, E. A. (2014). Urban Transport Environment and Equity: The case for developing countries. Routledge. 
The International Archives of the Photogrammetry, Remote Sensing and Spatial Information Sciences, Volume XLII-4/W12, 2019 5th International Conference on Geoinformation Science - GeoAdvances 2018, 10-11 October 2018, Casablanca, Morocco

Zha, Y., Gao, J., \& Ni, S. (2003). Use of normalized difference built-up index in automatically mapping urban areas from TM imagery. International Journal of Remote Sensing, 24(3), 583594. 